
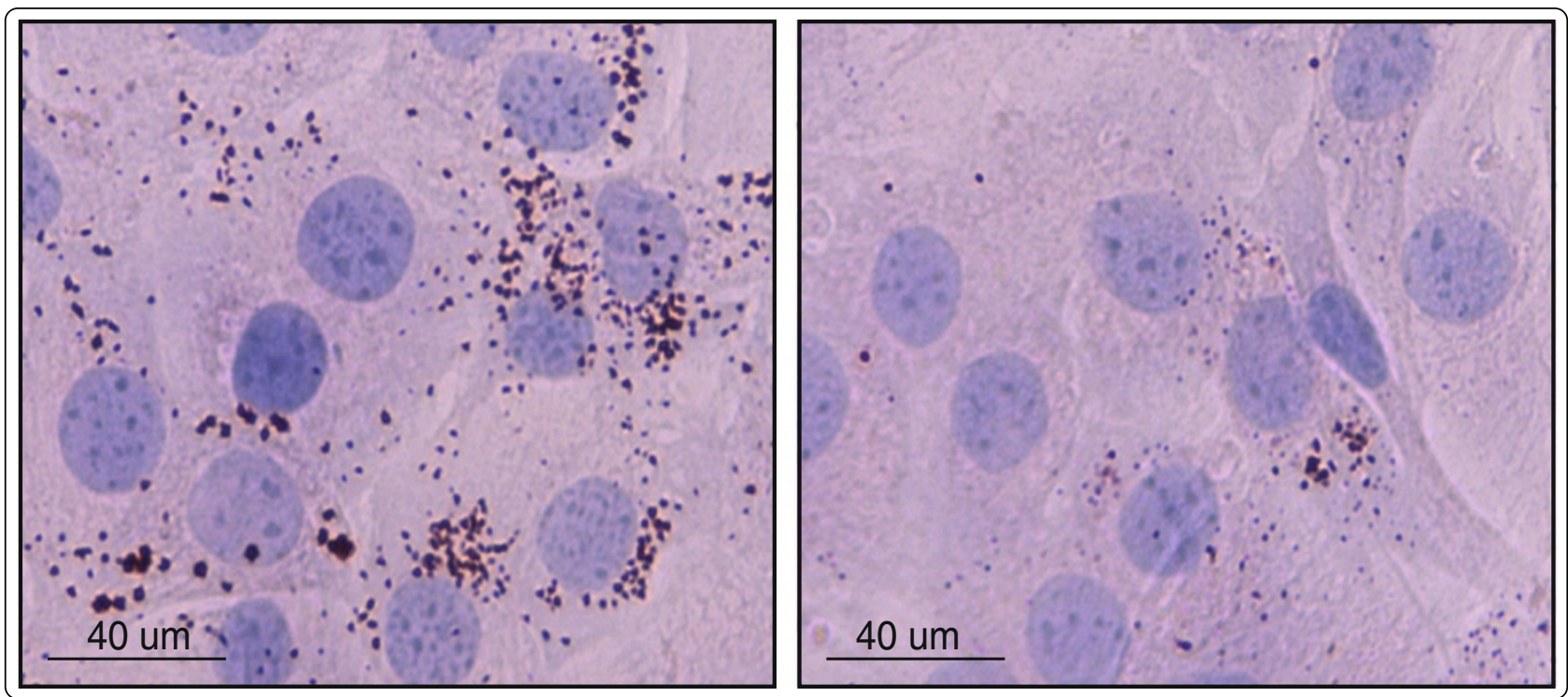

Eplerenone attenuated cardiac steatosis, apoptosis and diastolic dysfunction in experimental type-II diabetes

Ramírez et al. 


\title{
Eplerenone attenuated cardiac steatosis, apoptosis and diastolic dysfunction in experimental type-II diabetes
}

Elisa Ramírez ${ }^{1,2}$, Mercedes Klett-Mingo ${ }^{1,2}$, Sara Ares-Carrasco ${ }^{1}$, Belén Picatoste ${ }^{1,2}$, Alessia Ferrarini $^{4}$, Francisco J Rupérez ${ }^{4}$, Alicia Caro-Vadillo ${ }^{3}$, Coral Barbas ${ }^{4}$, Jesús Egido ${ }^{1,2}$, José Tuñón ${ }^{1 \dagger}$ and Óscar Lorenzo ${ }^{1,2^{*}}$

\begin{abstract}
Background: Cardiac steatosis and apoptosis are key processes in diabetic cardiomyopathy, but the underlying mechanisms have not been elucidated, leading to a lack of effective therapy. The mineralocorticoid receptor blocker, eplerenone, has demonstrated anti-fibrotic actions in the diabetic heart. However, its effects on the fatty-acid accumulation and apoptotic responses have not been revealed.

Methods: Non-hypertensive Zucker Diabetic Fatty (ZDF) rats received eplerenone $(25 \mathrm{mg} / \mathrm{kg})$ or vehicle. Zucker Lean $(Z L)$ rats were used as control ( $n=10$, each group). After 16 weeks, cardiac structure and function was examined, and plasma and hearts were isolated for biochemical and histological approaches. Cultured cardiomyocytes were used for in vitro assays to determine the direct effects of eplerenone on high fatty acid and high glucose exposed cells.

Results: In contrast to ZL, ZDF rats exhibited hyperglycemia, hyperlipidemia, insulin-resistance, cardiac steatosis and diastolic dysfunction. The ZDF myocardium also showed increased mitochondrial oxidation and apoptosis. Importantly, eplerenone mitigated these events without altering hyperglycemia. In cultured cardiomyocytes, high-concentrations of palmitate stimulated the fatty-acid uptake (in detriment of glucose assimilation), accumulation of lipid metabolites, mitochondrial dysfunction, and apoptosis. Interestingly, fatty-acid uptake, ceramides formation and apoptosis were also significantly ameliorated by eplerenone.
\end{abstract}

Conclusions: By blocking mineralocorticoid receptors, eplerenone may attenuate cardiac steatosis and apoptosis, and subsequent remodelling and diastolic dysfunction in obese/type-ll diabetic rats.

Keywords: Diabetic cardiomyopathy, Eplerenone, Steatosis, Apoptosis

\section{Introduction}

Type-II diabetes (T2DM) is an increasingly prevalent worldwide disease. Heart failure in these patients, even in the absence of vascular disease, is a common asymptomatic pathology known as diabetic cardiomyopathy (DCM). DCM is characterized by myocardial steatosis, apoptosis, and subsequent remodelling fibrosis and hypertrophy [1]. In addition, diverse comorbidities commonly present

\footnotetext{
* Correspondence: olorenzo@fjd.es

${ }^{\dagger}$ Equal contributors

'Cardiovascular Pathology laboratory, IIS-Fundación Jiménez Díaz, Autónoma University, Av. Reyes Católicos 2, Madrid 28040 Spain

${ }^{2}$ Spanish Biomedical Research Centre in Diabetes and Associated Metabolic Disorders (CIBERDEM) network, Madrid, Spain

Full list of author information is available at the end of the article
}

in diabetes, such as obesity, may accentuate these responses. In particular, overweight patients with T2DM have a significantly higher level of myocardial steatosis preceding and contributing to the early diastolic dysfunction [2]. The excess of circulating free fatty-acid (FFA) may result in increased cardiac FFA uptake, inadequate storage and metabolism, and consequent lipotoxicity by lipid metabolites such as ceramides and reactive oxygen species (ROS) [3]. However, the underlying molecular mechanisms have been poorly investigated, leading to a lack of a diagnostic method and effective therapy. In this sense, a pharmacological blockade of mineralocorticoid receptors (MR) could show potential benefits. MR are activated with equal affinity by aldosterone and glucocorti-

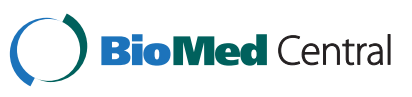


coids (mainly cortisol and corticosterone) [4]. Among them, aldosterone is a bioactive steroid of the major cardiovascular regulatory system: the renin-angiotensinaldosterone system (RAAS). Local RAAS activation has been associated with some hallmarks of the DCM, including fibrosis and apoptosis [5,6]. RAAS blockers based on angiotensin-II receptor inhibition improved fibrosis and diastolic dysfunction in asymptomatic diabetic patients [1]. However, given the pleiotropic role of angiotensin-II [7] the downstream RAAS effector aldosterone may be considered as an alternative target. In this regard, aldosterone promotes angiotensin-II actions and fibrosis in the diabetic myocardium by upregulation of pro-fibrotic and oxidative mediators [8]. Aldosterone exerts also apoptotic responses mainly by mitochondrial-dependent mechanisms [9], and these effects are worsened in hyperlipidemia and obesity $[1,6]$. Thus, eplerenone, a specific MR blocker, has demonstrated anti-fibrotic and anti-apoptotic properties in left ventricular hypertrophy, hypertension, and myocardial infarction $[8,10]$. Also, in controlled randomized clinical trials, eplerenone reduced mortality in patients with heart failure, independently of hypertension improvement and on top of angiotensin-II inhibition [11]. However, eplerenone actions on DCM and its related molecular mechanisms, particularly in steatosis and apoptosis, have not been elucidated.

\section{Methods}

\section{Animal model}

An obese non-hypertensive model of T2DM was used for this study (see Additional file 1). Zucker Diabetic Fatty (ZDF) rats lead to obesity and insulin resistance due to the inherited homozygous leptin receptor mutation $(f a / f a)$ [12]. At the $14^{\text {th }}$ week, male ZDF rats were randomized and received eplerenone [25 $\mathrm{mg} / \mathrm{kg} / \mathrm{day}$ ] or vehicle. $\mathrm{N}=10$, each group. Body weight and systolic blood pressure were monitored. After 16 weeks of treatment, blood and perfused hearts were isolated under anaesthesia. Plasma and renal parameters were measured in the Biochemistry Department of the Hospital. Hearts were rinsed, dried and weighted. Some ventricular slices were embedded in p-formaldehyde (to paraffin inclusion) or optimal-cutting-temperature (OCT) compound, for histology. Left ventricles were frozen in liquid- $\mathrm{N}_{2}$ for biochemical experiments. These investigations adhered to the Guide for the Care and Use of Laboratory Animals (NIH Publication No. 85-23, revised 1996) and the Ethics Committee of the hospital granted approval for these experiments.

\section{Cardiac structure and function}

Cardiac echocardiography was performed under 1.5\% isoflurane- $\mathrm{O}_{2}$ anaesthesia in all rats before (not shown) and after the treatment. Both M-mode and two-dimensional (2D) echocardiograms were obtained using a $12 \mathrm{MHz}$ ultra-band sector transducer (Doppler). Images were obtained from the left and right parasternal window in a supine decubitus position. The following parameters were measured and calculated from M-mode tracing: left ventricular (LV) end-diastolic diameter (LVDD), LV end-systolic diameter (LVSD), ejection fraction (EF), deceleration time and the ratio of the early (E) to late (A) ventricular filling velocities. Wall thickness of four segments [anterior, inter-ventricular-septum (IVS), lateral, and posterior (LVPW) walls] was evaluated on short axis $2 \mathrm{D}$ images.

\section{Examination of cardiac fibrosis, steatosis, apoptosis and oxidative stress}

Paraffin sections $(4 \mu \mathrm{m})$ of all myocardia were fixed on slides and used for histology (see Additional file 1). Cardiac fibrosis was evaluated by Masson trichrome (Bio-Optica, Milan, Italy) staining. All forms of fibrosis (interstitial, perivascular and replacement fibrosis) were quantified together on ten fields of each myocardium using the Metamorph software. For neutral triglycerides and lipids determination, frozen OCT-sections were sliced $(5 \mu \mathrm{m})$, immersed in propylene glycol and incubated in Oil red O (ORO) stain. Slides were transferred to propylene glycol and nuclear-counterstained with haematoxylin and mounted. Apoptosis was detected a TUNEL-based apoptosis detection Kit. The percentage of TUNEL-positive nuclei relative to total nuclei was determined in a blinded manner by counting 200-300 cells on ten randomly chosen fields per coverslip for each myocardium. Dihydroethidium (DHE; $5 \mu \mathrm{M}$, Invitrogen) was used to quantity cytosolic ROS production in paraffin-fixed myocardia. The average nuclear fluorescence intensity was measured in five fields of 50 cells by Metamorph. MitoSOX Red ( $5 \mu \mathrm{M}$, Invitrogen) was used to measure mitochondrial ROS production in myocardia. Paraffin sections were fixed on slides and incubated with MitoSOX Red (15 min at RT and darkness). Slides were stained 30' with 4',6-diamidino-2-phenylindole (DAPI), washed and mounted.

\section{Cultured cardiomyocytes}

H9c2(2-1) is a permanent myoblast cell line derived from embryonic BD1X rat heart tissue (ATCC; USA). H9c2 were grown at $37^{\circ} \mathrm{C}$ in $5 \% \mathrm{CO}_{2}$ in Dulbecco's modified Eagle's medium supplemented with $10 \%$ heat-inactivated foetal calf serum, $100 \mathrm{IE} / \mathrm{ml}$ penicillin, $100 \mu \mathrm{g} / \mathrm{ml}$ streptomycin, $2 \mathrm{mM} \mathrm{L}$-glutamine and $5 \mathrm{mM}$ D-glucose (Sigma). H9c2 differentiated from mononucleated myoblasts into myocytes upon overnight reduction of serum concentration before stimulation. Mouse C2C12 myoblasts (ATCC, USA) were kindly given by Dr. Konhilas (University of 
Arizona, USA) and maintained in DMEM supplemented with $10 \%$ foetal calf serum, $50 \mathrm{U} / \mathrm{ml}$ penicillin, and $50 \mu \mathrm{g} / \mathrm{ml}$ streptomycin. Before confluency, the medium was switched to the differentiation medium containing DMEM and 2\% horse serum. After four additional days, the differentiated $\mathrm{C} 2 \mathrm{C} 12$ cells fuse into myotubes. The hyperlipidemic or hyperglycemic conditions were mimicked by incubation with high concentrations of a common saturated FFA $\left(\mathrm{Na}^{+}\right.$-palmitate, 16:0, 0.12-0.25 mM, Sigma) or glucose (D-glucose, $33 \mathrm{mM})$, respectively, for $12 \mathrm{~h}$ (protein expression) or $6 \mathrm{~h}$ (mRNA expression). Palmitate was previously conjugated with BSA in a 3:1 molar ratio as published elsewhere [13]. In control cells, BSA was added as described but in the absence of palmitate. Eplerenone $(1 \mathrm{mM}-1 \mu \mathrm{M})$ was added $1 \mathrm{~h}$ before stimulation.

\section{Glucose uptake}

For glucose uptake evaluation, cardiomyocytes were grown under normal conditions and incubated for 3 hours with 100 4M 2-(N-(7-nitrobenz-2-oxa-1,3-diazol-4-yl)-amino-2deoxyglucose (2-NBDG; Invitrogen) and HF or insulin, as a positive control. After discharging media and washing the cells, fluorescence was measured in the cytometer.

\section{ATP determination}

Cellular ATP levels were quantified using a luciferase-based assay. Cardiomyocytes were exposed to HF (+/- eplerenone pre-treatment), after which, cells were rinsed with PBS and lysed with ATP-releasing buffer $\left(100 \mathrm{mM} \mathrm{KH_{2 }} \mathrm{PO}_{4}\right.$, $2 \mathrm{mM}$ EDTA, $1 \mathrm{mM}$ dithiothreitol, and 1\% Triton X-100 at $\mathrm{pH}$ 7.8). Ten $\mu \mathrm{l}$ of the lysate were taken for protein determination and another ten $\mu \mathrm{l}$ were used for ATP quantification using the ATP determination kit (Invitrogen), according to the manufacturer's instructions.

\section{Detection of lipid-accumulation, apoptosis/survival and oxidation in cardiomyocytes}

For cell steatosis quantification, after $12 \mathrm{~h}$ of stimulation cells were methanol-fixed and stained with ORO, as it was in myocardia. Lipid accumulation was semi-quantified by using Metamorph software on five fields of stimulated cells of at least three independent assays. Apoptosis was quantified by flow cytometry of cell DNA content (see Additional file 1). After stimulations, cells were harvested, permeabilized and DNA-stained with propidium iodide. The percentage of apoptotic cells is shown. Cells were also cultured in chamber slides, stimulated, fixed and nuclear-stained with DAPI. Condensed, piknotic and fragmented nuclei of apoptotic cells were identified by confocal microscopy (see Additional file 1). Cell survival was achieved with a MTT [3-(4,5-dimethylthiazol-2-yl)2,5-diphenyltetrazolium bromide] Cell Growth Assay Kit, following manufacture's instructions. MitoSOX Red was used to quantify mitochondrial ROS production.
Cardiomyocytes were fixed on slides and incubated with MitoSOX Red, as it was in hearts. In addition, mitochondrial superoxide was evaluated by flow cytometry. Cells were grown in 10\% FBS-DMEM without red phenol until sub-confluency. After overnight starvation, cells were stimulated, loaded with MitoSOX Red as it was in myocardia, and trypsin-detached. Cells were counted in the cytometer. Red fluorescence was measured at several intervals of time from confocal images. One $m M \mathrm{H}_{2} \mathrm{O}_{2}$ was used as control (data not shown).

\section{Lipid quantification}

Portions of left ventricle myocardium or $\sim 8 \times 10^{5}$ stimulated cardiomyocytes were dissolved in were dissolved in $25 \mu \mathrm{L}$ ethanol/mg or $100 \mu \mathrm{L}$ ethanol, respectively. One glass bead (acid-washed, $2 \mathrm{~mm}$, Sigma) was added to every tube and lipids were then extracted by vigorous shaking with a TissueLyser LT from Qiagen (Hilden, Germany) for $5 \mathrm{~min}$, at $50 \mathrm{rpm}$. Tubes were further centrifuged at $15,400 \mathrm{~g}$ and $15^{\circ} \mathrm{C}$ for $20 \mathrm{~min}$, and $80 \mu \mathrm{L}$ from the supernatant were transferred to Ultra High Performance Liquid Chromatography-Mass (UHPLC-MS) spectrometry vials with insert. Quantitative evaluation of the proportion of lipids was performed by a spectrometer from Agilent Technologies (Santa Clara, CA, USA), equipped with a 1290 series LC system and a 6550 iFunnel QTOF MS detector. One $\mu \mathrm{L}$ from each sample was injected (three times) onto the column, a Zorbax Eclipse Plus C8, $2.1 \times 150 \mathrm{~mm}$; $1.8 \mu \mathrm{m}$ (Agilent Technologies) kept at $80^{\circ} \mathrm{C}$. Compounds were eluted with an $8 \mathrm{~min}$ linear gradient for the mobile phase at $0.6 \mathrm{~mL} / \mathrm{min}$, from $50 \%$ ammonium formate $10 \mathrm{mM}(\mathrm{pH}$ 6.5) and 50\% Methanol to $100 \%$ Methanol. Conditions, reagents, as well as the procedure for data processing in order to obtain a list of abundances of all the lipids of interest are provided in Additional file 1.

\section{Western blot and ELISA}

A piece $(50 \mathrm{mg}$ ) of homogenized ventricle (Bullet Blender, Cultek) or cell extract were dissolved in cold lysis buffer (see Additional file 1). Equal amounts of proteins (20$30 \mu \mathrm{g}$ ) were separated on polyacrylamide gels, transferred to membranes and probed with primary antibodies. Secondary HRP-linked antibodies (GE Healthcare) were used for chemo-luminescence development. A representative gel of all rats or at least three independent experiments of cultured cells with the semi-quantification scores (n-fold vs. GAPDH) are shown. Following manufacture's guidelines, rat endogenous aldosterone and glucocorticoids ELISA kits (antibodies-online.com) were used for aldosterone and glucocorticoids detection in cultured media, respectively. Plasma insulin was detected using a rat insulin ELISA kit (Mercodia, Sweden). 


\section{Quantitative-PCR (QPCR)}

Total RNA was extracted from homogenized ventricle (50 mg) or cultured cardiomyocytes by dissolving in Trizol reagent (Invitrogen). Equal amounts of RNA $(1 \mu \mathrm{g})$ were reverse-transcripted to obtain the cDNA for multiplex QPCR with specific probes (see Additional file 1). We show a quantification ( $\mathrm{n}$-fold vs. $18 \mathrm{~s}$ ) of at least two QPCRs of all rats or three independent cultured cardiomyocytes experiments.

\section{Statistical analysis}

Data are expressed as mean \pm standard deviation. Multiple comparisons were performed by non-parametric KruskalWallis test followed by a Mann-Whitney test. A two-tailed $\mathrm{p}<0.05$ was considered significant.

\section{Results}

\section{Reduction of hyperlipidemia by eplerenone in obese/T2DM rats}

After 30 weeks, ZDF rats exhibited high plasma levels of aldosterone, glucose, insulin and lipid profile (Figure 1A). Interestingly, 16 weeks of eplerenone substantially triggered plasma aldosterone and reduced plasma lipids. No significant changes in systolic blood pressure $(135.0 \pm 8.1$ vs. $139.8 \pm 15.2 \mathrm{~mm} \mathrm{Hg}$ for ZL and ZDF rats, respectively) were observed. Markers of severe renal (urea, blood urea nitrogen, creatin and albumin) and liver (aspartyl and alanine aminotransferases) injury remained within the normal ranges in all groups (not shown). Of note, since mineralocorticoid antagonists may induce hyperkalemia [14], we monitored plasma potassium concentrations. Conveniently, at this dose/time of eplerenone, potassium was kept within the non-toxic levels in all rats $(4.4 \pm$ $0.58 \mathrm{mEq} / \mathrm{l})$.

\section{Attenuation of cardiac hypertrophy and diastolic dysfunction by eplerenone in ZDF rats}

As previously documented [15], at this stage of the disease ZDF rats exhibited weight loss. However, a significant elevation of the heart weight/femur length (HW/FL) ratio was observed (Figure 1A). Moreover, by Echo-Doppler (Figure 1B), ZDF hearts exhibited an increase of the inter-ventricular septum (IVS) thickness, and a reduction of left ventricular diastolic (LVDD) and systolic (LVSD) diameters, probably related to IVS hypertrophy. In this sense, the mRNA expression of atrial natriuretic peptide (ANP), a molecular marker of hypertrophy, was increased in the left ventricle of ZDF (Figure 1C). Brain natriuretic peptide (BNP) was, however, not significantly modified in the rats (not shown). In addition, ZDF showed a prolongation of the deceleration time and decreased E/A ratio, suggesting diastolic dysfunction. However, the ejection fraction (EF) was unchanged. Interestingly, the altered HW/FL, IVS, ANP expression, deceleration time and E/A ratio were attenuated by eplerenone administration.

\section{Eplerenone ameliorated fibrosis and apoptosis in the ZDF myocardium}

Left ventricular myocardium in the ZL rats exhibited a normal architecture with regular interstitial space. However, abnormal myocardial architecture (cardiomyocyte hypertrophy and disarray, and enlarged interstitial space) was observed in the ZDF group (Additional file 2: Figure S1A). Confirming previous data in experimental [16] and human [17] diabetes, the deposition of interstitial and mainly perivascular extra-cellular matrix (ECM), and the increase of pro-fibrotic factors such as type-IV collagen and fibronectin, were attenuated by eplerenone (Additional file 2: Figure S1A, B). More interestingly, since both hypertrophy (Figure 1A-C) and fibrosis (Additional file 2: Figure S1A, B) may contribute to myocardial remodelling in response to a loss of cells $[6,18]$, we focused on the apoptotic response of ZDF hearts and their treatment with eplerenone. By TUNEL (Figure 2A), we observed an increase of apoptotic-positive nuclei in ZDF (4.1 vs. 1.2 cells $/ \mathrm{mm}^{2} \mathrm{ZL}$ ), which was reduced by eplerenone. Moreover, ZDF showed an activation of pro-apoptotic caspase-3, and eplerenone mitigated this response (Figure $2 \mathrm{~B}$ ).

\section{Eplerenone decreased apoptosis in high fatty acid-stimulated cardiomyocytes}

To elude the confounding effects of reduced hyperlipidemia on the eplerenone-treated ZDF myocardium, we tested the apoptosis response in eplerenone-pretreated cultured cardiomyocytes exposed to high concentrations of a saturated fatty acid (HF) and/or glucose (HG). In our conditions, HF, but not HG, significantly increased the number of apoptotic cardiomyocytes as early as $14 \mathrm{~h}$ incubation and at $0.12 \mathrm{mM}$ (Additional file 2: Figure S1C), similarly to a lethal cytokine $(30 \mathrm{U} / \mathrm{ml} \mathrm{IFN \gamma}$; not shown). In addition, caspase- 3 activation and subsequent nuclear pyknosis and cell loss were detected mainly in HF-incubated cardiomyocytes (Additional file 2: Figure S1D). HF and HG co-incubation did not significantly alter the magnitude of HF-induced apoptosis. In addition, HF induced the release of aldosterone from cardiomyocytes to the cultured media (Additional file 3: Figure S2), and thus, eplerenone may block aldosterone-associated actions on cultured cardiomyocytes. In fact, eplerenone $(1 \mu \mathrm{M})$ reduced HF-induced cell apoptosis and caspase3 activation (Figure 3A, B). These data were confirmed by MTT survival assays. Incubation with HF significantly decreased the cardiomyocytes viability (black bars) and this effect was mitigated by eplerenone (only for $0.12 \mathrm{mM}$; Figure 3C). HG and eplerenone alone did not modify the survival rates. 
A

Plasma:

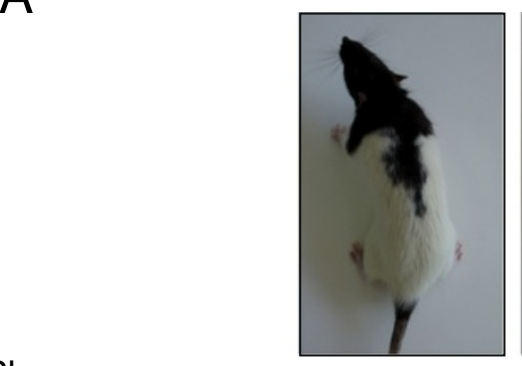

Aldosterone $(\mathrm{pg} / \mathrm{ml}) 180 \pm 57.19$

Glucose (mg/dl) $194.55 \pm 38.2$

Insulin (ng/mL) $1.08 \pm 0.11$

Ch $(\mathrm{mg} / \mathrm{dl}) 61.11 \pm 8.35$

TAG (mg/dl) 39.66 \pm 8.36

FFA (mM) $1.61 \pm 1.15$

HDL (mg/dl) 19.77 \pm 2.33

Ch non-HDL (mg/dl) $41.33 \pm 6.53$

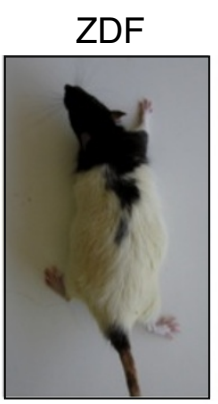

$430 \pm 192.63^{*}$

$66 \pm 102.61^{* *} 697.51 \pm 89.8$

$1.83 \pm 0.24^{*}$

$2.00 \pm 0.28$

$187.16 \pm 14.13^{* *} 143.4 \pm 12.26$ t十

$397.66 \pm 166.87^{* *} 111.7 \pm 33.21^{\dagger+}$

$5.17 \pm 1.19^{* *}$

$0.73 \pm 0.3^{t \dagger}$

$76.5 \pm 10.36^{* *}$

$73.2 \pm 12.26$

$112.33 \pm 14.05^{* *} \quad 111.75 \pm 32.8$

Weight (g) HW/FL

$431.9 \pm 26.73$
$0.41 \pm 0.03$

$341.14 \pm 38.71^{* *} 338.25 \pm 70.26$

$0.55 \pm 0.06^{*}$

$0.47 \pm 0.01^{\dagger}$
B

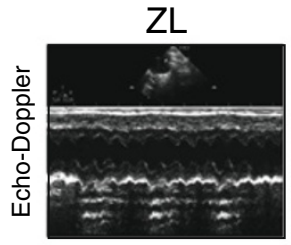

$\operatorname{LVPW}(\mathrm{cm})$

IVS $(\mathrm{cm}) \quad 0.18 \pm 0.029$

LVDD $(\mathrm{cm}) \quad 0.71 \pm 0.10$

LVSD (cm) $0.32 \pm 0.097$

EF (Teich) $\quad 0.88 \pm 0.07$

Dec. T (s) $\quad 0.036 \pm 0.001$

E/A ratio

$1.22 \pm 0.03$

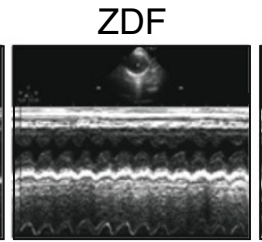

$0.23 \pm 0.034$

$0.24 \pm 0.015^{* *}$

$0.51 \pm 0.115$ *

$0.21 \pm 0.076^{*}$

$0.9 \pm 0.07$

$0.04 \pm 0.003^{*}$

$1.05 \pm 0.03^{*}$

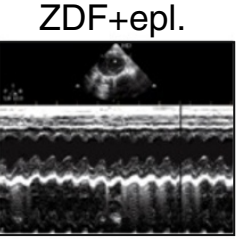

$0.22 \pm 0.03$

$0.2 \pm 0.032^{\dagger}$

$0.5 \pm 0.078$

$0.22 \pm 0.061$

$0.85 \pm 0.09$

$0.031 \pm 0.005^{\dagger}$

$1.18 \pm 0.02^{\dagger}$

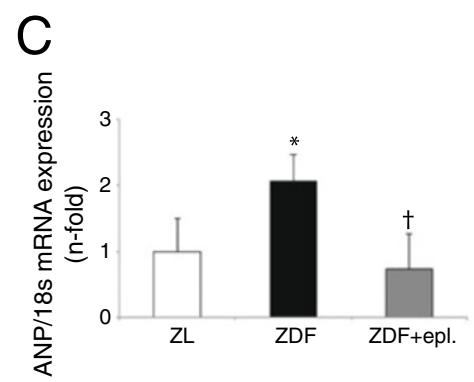

Figure 1 Eplerenone improved hyperlipidemia and cardiac hypertrophy in ZDF rats. After sixteen weeks of treatment, (A) physical and plasmatic parameters, and (B) cardiac structure and function in ZL, ZDF and ZDF-treated rats ( $n=10$, each group). Representative photographs of rats and Echo-Doppler images for each group are also shown. (C) Pro-hypertrophic ANP expression in the hearts. Ch, cholesterol; TAG, triglycerides; FFA, free fatty-acid; HDL, high-density lipoproteins; HW, heart weight; FL, femur length. LVPW, left-ventricular posterior wall and IVS, inter-ventricular septum (IVS) thicknesses; LVDD, left ventricular diastolic and LVSD, left ventricular systolic diameters; EF, ejection fraction and Dec. T, deceleration time. ${ }^{*} p<0.05$ and ${ }^{* *} p<0.01$ vs. ZL. $+p<0.05$ and $+t p<0.01$ vs. ZDF rats. 

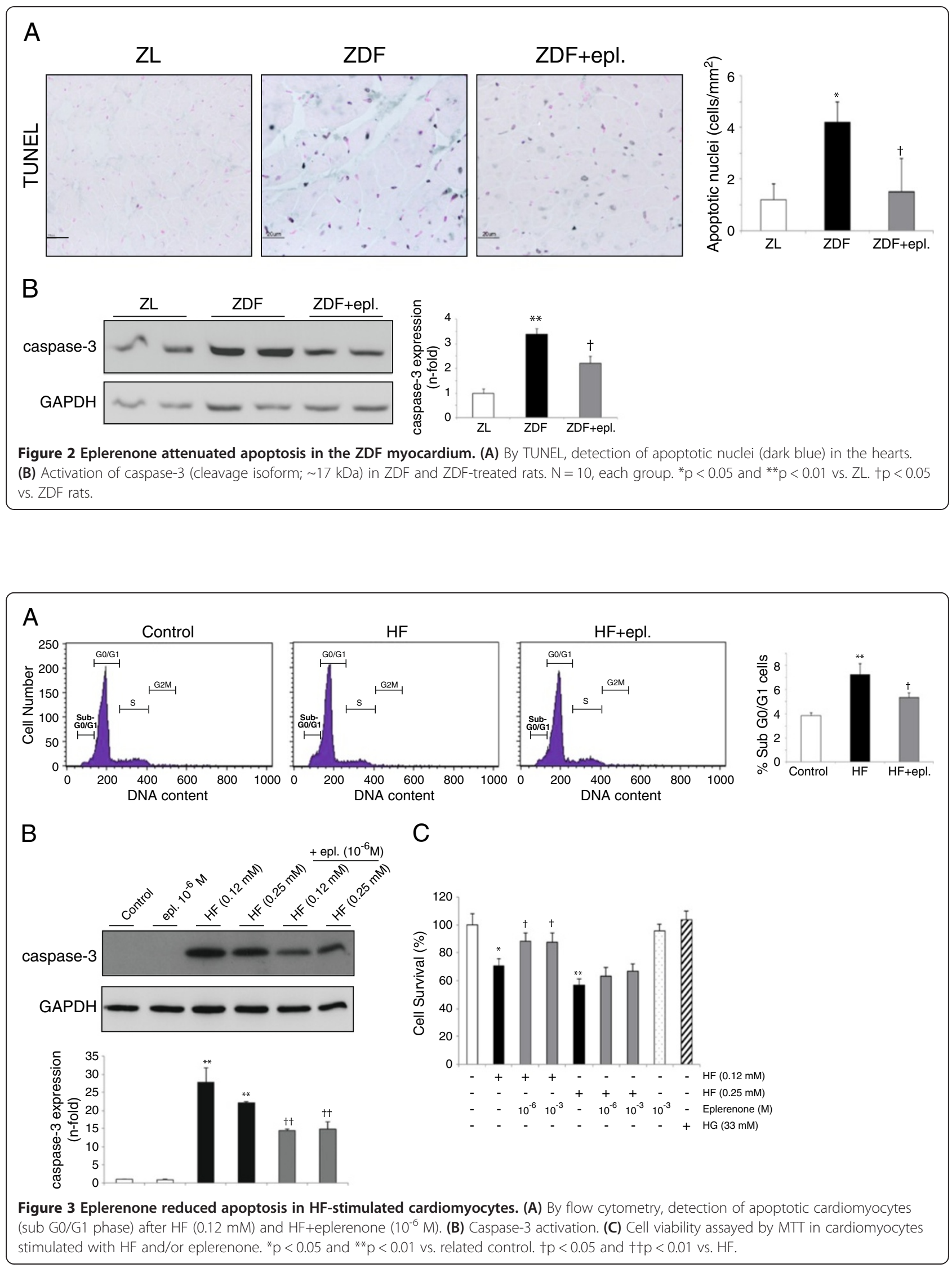

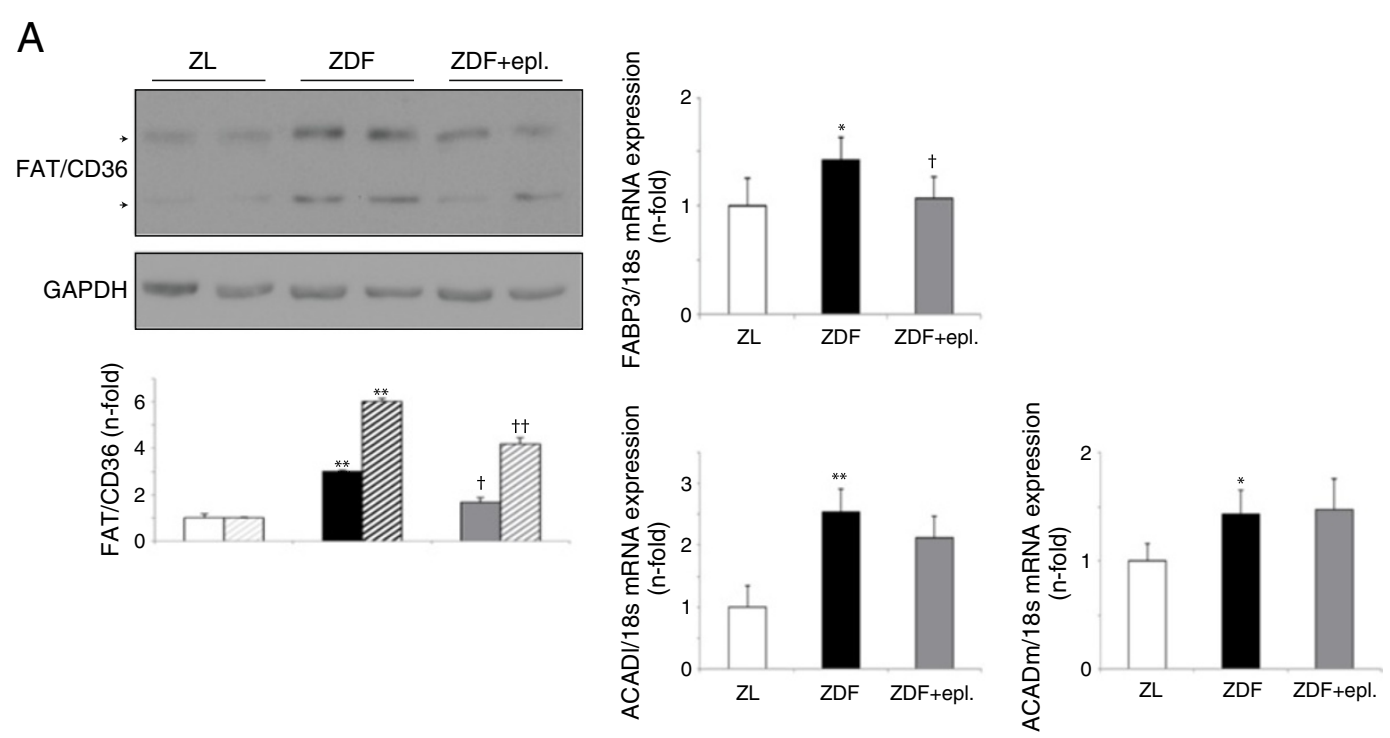

B
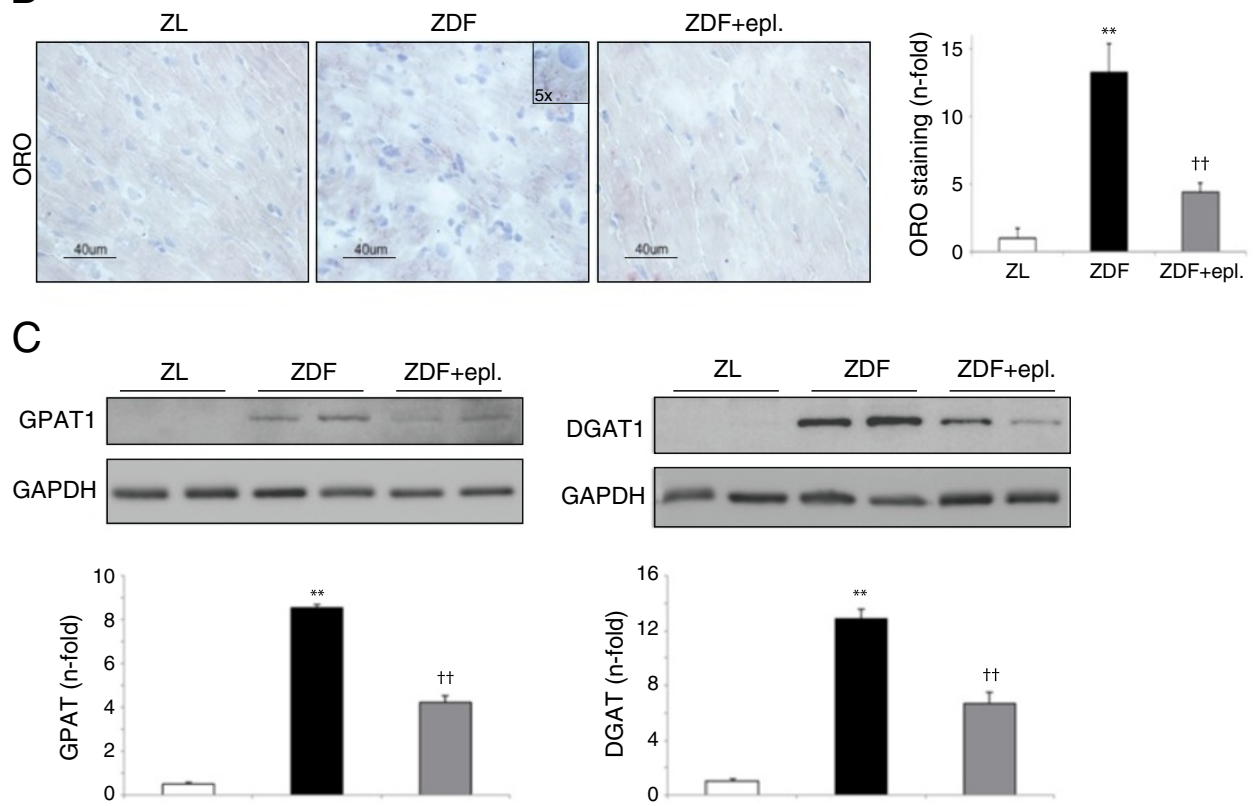

$\mathrm{D}$
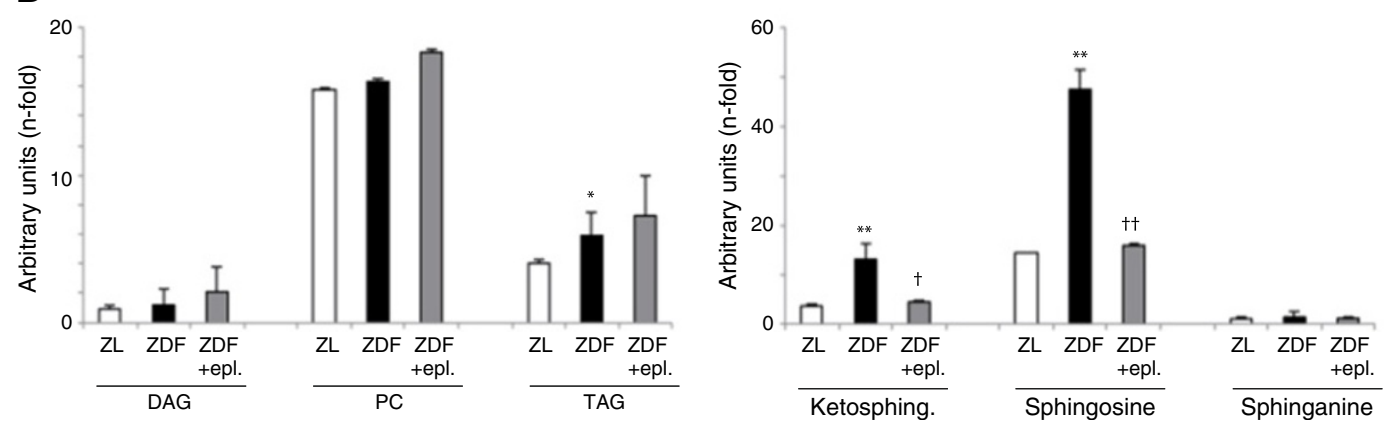

Figure 4 (See legend on next page.) 

solid bars and broken bars in the quantification graph, respectively) expression in ZL, ZDF and ZDF+eplerenone hearts. Right, FABP3, ACADI and ACADm mRNA expression. (B) Detection of intra-cellular lipid deposition (steatosis) in the rats by ORO staining. A detailed $5 x$ magnification of the lipid droplets is shown in ZDF. (C) Protein levels of GPAT1 ( 90 kDa) and DGAT1 ( 52 kDa) in rat myocardia. (D) By UHPLC-MS, DAG, phosphatidyl-choline $(\mathrm{PC}), \mathrm{TAG}$, and ketosphingosine, sphingosine and sphinganine levels. ${ }^{*} \mathrm{p}<0.05$ and ${ }^{* *} \mathrm{p}<0.01 \mathrm{vs}$. ZL. $+\mathrm{p}<0.05$ and $+\dagger p<0.01 \mathrm{vs}$. ZDF rats.

\section{Eplerenone reduced myocardial steatosis in ZDF hearts} Apoptosis in obese/T2DM hearts may result from an excessive uptake and accumulation of FFA $[3,18]$. The main cardiac FFA protein-transporter is FAT/CD36, which traffic from intracellular stores (endosomes) to the sarcolemma to facilitate FFA uptake [19]. Indeed, FAT/CD36 isoforms, likely corresponding to the nonglycosylated (lower) and glycosylated/phosphorylated (upper) proteins [20], were increased in the ZDF myocardium (Figure 4A, left). Next, FFA can deliver to different organelle, primarily to mitochondria for energy consecution. In this regard, ZDF showed elevated mRNA expression of a FFA-cytosolic transporter, the FFA-binding protein-3 (FABP3; Figure 4A, right) and two main $\beta$ oxidation enzymes, $\mathrm{ACADl}$ and $\mathrm{ACADm}$ (large chain- and medium chain- acyl-CoA dehydrogenases, respectively) (Figure 4A, right). However, as a consequence of high FFA-uptake (or uncoupled FFA-uptake and oxidation), FFA can be stored by re-esterification as TAG and phospholipids in the cytosol of obese/T2DM cardiomyocytes [21]. In this sense, we identified numerous cytosolic lipid droplets (Figure 4B) in ZDF myocardia, typically from myocardial steatosis. Also, ZDF up-regulated two rate-limiting enzymes of lipid re-esterification, GPAT1 (glycerol-3phosphate acyltransferase-1) and DGAT1 (DAG acyltransferase-1) (Figure 4C), and increased TAG content (Figure 4D, left). Then, if this accumulation persists overt time, lipids may diverge to lipotoxic metabolites such as ceramides [22,23]. In this regard, ZDF hearts accumulated sphingolipids precursors of ceramides such as ketosphingosine and sphingosine (Figure 4D, right). Interestingly, eplerenone lessened the expression/translocation of FAT/ CD36 and FABP3, myocardial steatosis, GPAT1/DGAT1, and ceramides intermediates (Figure 4A-D).

\section{Eplerenone decrease lipid metabolism and accumulation in HF-stimulated cardiomyocytes}

Cardiac steatosis was confirmed in HF-incubated cardiomyocytes by Oil Red-O staining (Figure 5A). However, previous data had suggested that $\mathrm{H} 9 \mathrm{c} 2$ cells might not express FAT/CD36 receptor [24]. Thus, we used another cell line of myocytes with demonstrated FAT/CD36 expression and activated lipid metabolism [25]. C2C12 cells increased also lipid droplets (not shown), and up-regulated glycosylated/phosphorylated FAT/CD36 isoforms after HF incubation, possibly corresponding to its sarcolemma translocation (Figure 5B). Downstream, FABP3 and $\mathrm{ACADl} / \mathrm{ACADm}$ transcripts were augmented by HF (Figure 5C). GPAT1/DGAT1 (Figure 5D, top), DAG, phospholipids (phosphatidyl-choline) and sphingosine were also increased (Figure 5D, bottom). However, in agreement with ZDF-treated rats, eplerenone mitigated cytosolic lipid accumulation, FAT/CD36 and FABP3 after HF (Figure 5A-C). Eplerenone reduced also DGAT1 and sphingosine (Figure 5D). These data suggest a direct effect of eplerenone on lipid uptake and storage at the myocardium.

By other hand, unsurprisingly, HG did not induce steatosis in cardiomyocytes (not shown). However, the stimulated lipid storage and metabolism could affect glucose utilization [21]. In this sense, as soon as $3 \mathrm{~h}$ of HFincubation, C2C12 exhibited a significant decrease of glucose uptake that was reverted by eplerenone (Figure $5 \mathrm{E}$ ).

\section{Eplerenone improved DCM-associated mitochondrial stress but not mitochondrial regulators}

Apoptosis in the obese/T2DM heart has been also related to an overproduction of reactive oxygen species (ROS), which damages cell mitochondria and induce apoptosis [3]. In our model, ZDF showed an increase of cytosolic (Figure 6A, left) and mainly mitochondrial (Figure 6A, right) superoxide production, but eplerenone attenuated these levels. These data were confirmed in cultured cardiomyocytes. By flow cytometry (Figure 6B, left) and immunofluorescence (Figure 6B, right), HF induced mitochondrial-ROS formation as early as $10 \mathrm{~min}$ of stimulation, and eplerenone prevented this effect. Consistently, mitochondrial ATP production was decreased in HF-incubated cardiomyocytes $(0.25 \mathrm{mM})$, and restored after eplerenone treatment (Figure 6C).

More interestingly, the levels of key regulators of mitochondrial function such as the complex peroxisome proliferator activated receptor- $\alpha$ (PPAR $\alpha) /$ PPAR $\gamma$ coactivator $-1 \alpha(\mathrm{PGC} 1 \alpha)$, and related transcription factors involved in mitochondrial biogenesis and oxidative metabolism, such as the mitochondrial transcription factor-A (Tfam) and the nuclear respiratory factor-1 (NRF1) [26], were significantly reduced in ZDF hearts (Figure 7A-B). However, only PPAR $\alpha \omega \alpha \sigma$ restored by eplerenone. Interestingly, HF $(0.25 \mathrm{mM})$ did not alter PPAR $\alpha / P G C 1 a$ (not shown), but reduced the content of Tfam and NRF1 in H9c2. Again, eplerenone could not prevent these responses (Figure 7C). 


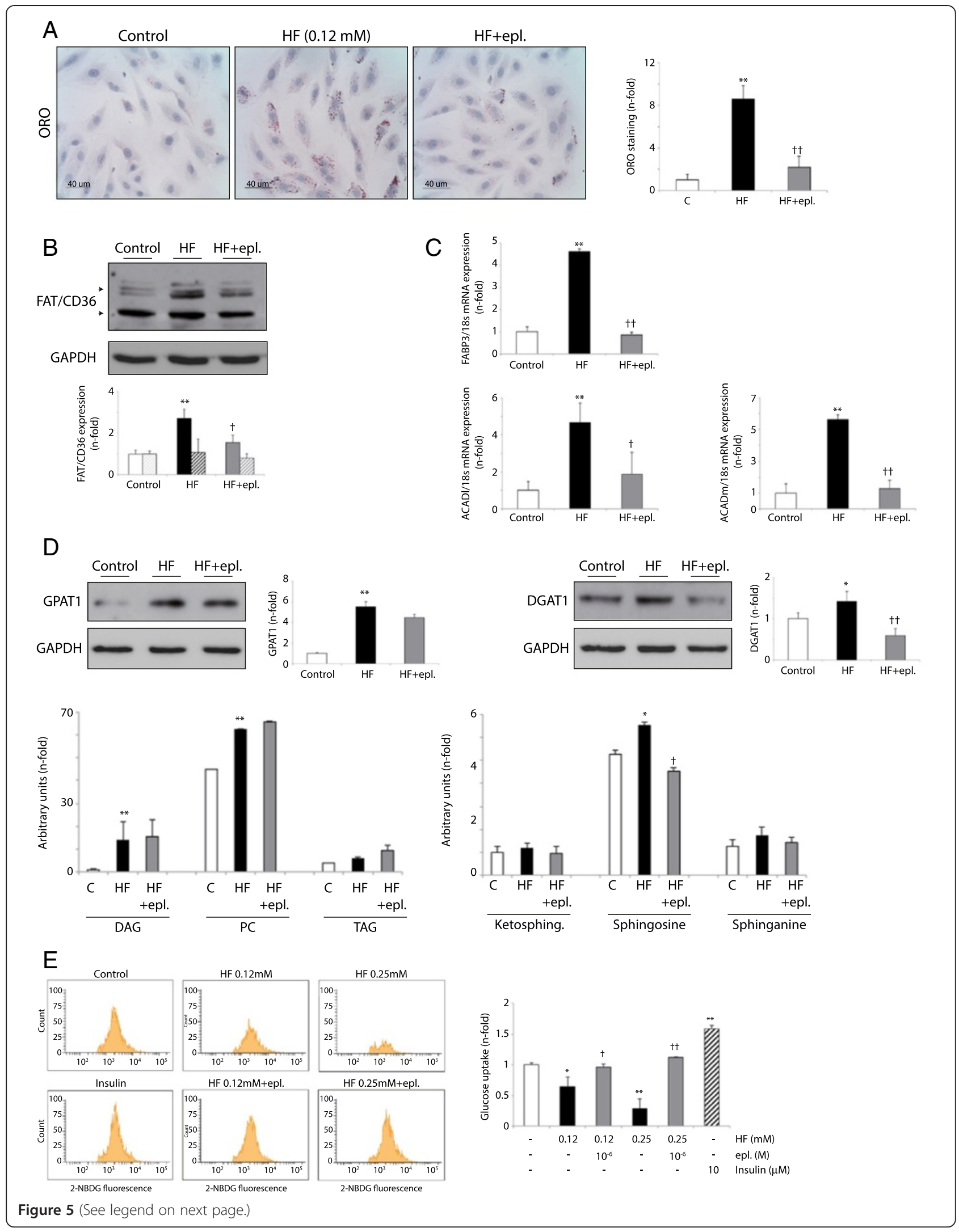


(See figure on previous page.)

Figure 5 Eplerenone reduced lipid metabolism and ceramides formation in cultured cardiomyocytes. (A) Lipid accumulation in control, HF- and HF+eplerenone-treated H9c2. (B) FAT/CD36 protein content in C2C12 myotubes ( $90 \mathrm{kDa}$ and $\sim 53 \mathrm{kDa}$; solid bars and broken bars in the quantification graph, respectively). (C) FABP3, ACADI and ACADm transcript levels. (D) Top, GPAT1 and DGAT1 protein expression. Bottom, DAG, PC, TAG, and ketosphingosine, sphingosine and sphinganine levels by UHPLC-MS. (E) Eplerenone improved glucose assimilation in HF-incubated C2C12. Eplerenone was pre-administrated in some HF- or insulin-stimulated cells, and 2-NBDG was evaluated. ${ }^{*} p<0.05$ and ${ }^{* *} p<0.01$ vs. related control. $t p<0.05$ and $+t p<0.01$ vs. related $H F$.

\section{Discussion}

Elevated content of lipids in cardiac muscle, and following increase of apoptosis and ECM deposition are distinctive of human and experimental DCM. These abnormalities may generate cardiac hypertrophy and dysfunction, eventually leading to congestive heart failure $[1,21]$. Chronic obese/T2DM rats exhibited cardiac steatosis, apoptosis, fibrosis and hypertrophy, and diastolic (but not systolic) dysfunction. In DCM, diastolic dysfunction is not necessary accompanied with a reduction of EF [12,27], or it occurs earlier than systolic alteration [28]. Nevertheless, a valid treatment for DCM patients is needed. As we confirmed here, the blockade of MR has emerged as an effective anti-fibrotic therapy in DCM $[5,29]$. However, we also claim it might induce anti-steatosis and antiapoptosis actions, contributing to the recovery of diastolic function [2].

Long-term hyperglycemia promotes negative effects on the heart, affecting the cardiac expression of lipid-, glucose- and ketone bodies-metabolic, signalling and stress-response genes [30,31]. Chronic hyperglycemia is related with cardiac fibrosis, coronary disease and increased risk of heart attack, and it has been also associated with higher levels of toxic glycolytic intermediates and troponin-T, a blood marker for heart damage [32]. However, recent clinical trials have revealed non-significant advances of intensive glycemic control on the mortality of DCM patients with cardiovascular events [33], suggesting that other events such as lipotoxicity may be targeted for new therapies. In this sense, eplerenone reduced hyperlipidemia without altering hyperglycemia in ZDF rats (Figure 8). Similar data were found in obese/T2DM mice [34], and individuals with essential hypertension [35]. Thus, the anti-hyperlipidemic actions of eplerenone could be independent of changes in glycemia or blood pressure [36], and possibly due in part to an improvement of insulin resistance. After MR blockade, experimental and clinical studies have demonstrated an increase of the insulin response by reduction of redox-sensitive and -insensitive serine kinases, and consequent activation of IRS-1 signaling. Also, the MR blockade increased both insulin and glucose receptor genes, leading to improved glucose uptake [37] [38]. Here we also showed a restoration of IRS-1 levels (Additional file 3: Figure S2B) and glucose uptake in eplerenone-treated ZDF or HF-exposed cardiomyocytes, respectively. Nevertheless, the role of eplerenone on lipid intestinal absorption and release from adipose tissue is not clarified. In this sense, eplerenone prevented adiponectin reduction and leptin elevation of adipose tissue in obese/T2DM mice [34].

The attenuated plasma lipid availability could bring about a reduction of lipid deposition within the heart. However, we found potential direct anti-steatotic effects in DCM (Figure 8). The expression/sarcolemma relocation of FAT/CD36 (and FABP3) was ameliorated with eplerenone in ZDF hearts, but also in HF-incubated cardiomyocytes. Interestingly, FAT/CD36, FABP3, and several $\beta$-oxidation enzymes, are transcriptional targets of PPAR $\alpha$ [39], however, PPAR $\alpha$ was elevated after eplerenone in ZDF hearts. The metabolic changes associated to the activity of PPAR $\alpha$ may depend on the stage of obesity and diabetes $[40,41]$. Chronic exposure to elevated FFA reduced PPAR $\alpha$ in cardiomyocytes, and this effect was proposed to further decrease cardiac function and increase intracellular fat stores [21]. Also, the PPAR-response elements were not identified on FAT/CD36 gene [42], and PPAR $\alpha$ may need specific coactivators such as PGC1 $\alpha$ to mediate these actions [43]. Of interest, PGC1 $\alpha$ was also not stimulated in ZDF. Next, we observed an increase of cytosolic lipid droplets and activation of lipid re-esterification in ZDF myocardia and HF-incubated cardiomyocytes (Figure 8). This effect may be related to the rise of TAG, and DAG and PC, respectively. Moreover, we detected an accumulation of sphingosine in both ZDF myocardia and HF-exposed cells. The increased lipogenic capacity $[21,44]$, and overall, the cardiac deposition of ceramides could promote insulin resistance, lipoapoptosis and dysfunction in the ZDF heart [22,23]. However, eplerenone reduced lipid droplets, lipid re-esterification enzymes and ceramides formation, likely contributing to the improved diastolic dysfunction (Figure 8).

Finally, a lipid overload together with a reduction in glucose assimilation may also result in non-neutralized mitochondrial ROS production and apoptosis in DCM (our data and [41]). In ZDF myocardia and HF-exposed cardiomyocytes we have described an increase of cytosolic and mainly mitochondrial ROS, consequent ATP deficiency, and apoptosis. These levels correlated with the reduced expression of PPAR $\alpha / \mathrm{PGC} 1 \alpha$ complex and linked transcription factors (Tfam and NRF1). Interestingly, eplerenone attenuated ROS levels, ATP deficiency and apoptosis, without altering these mitochondrial regulators, 

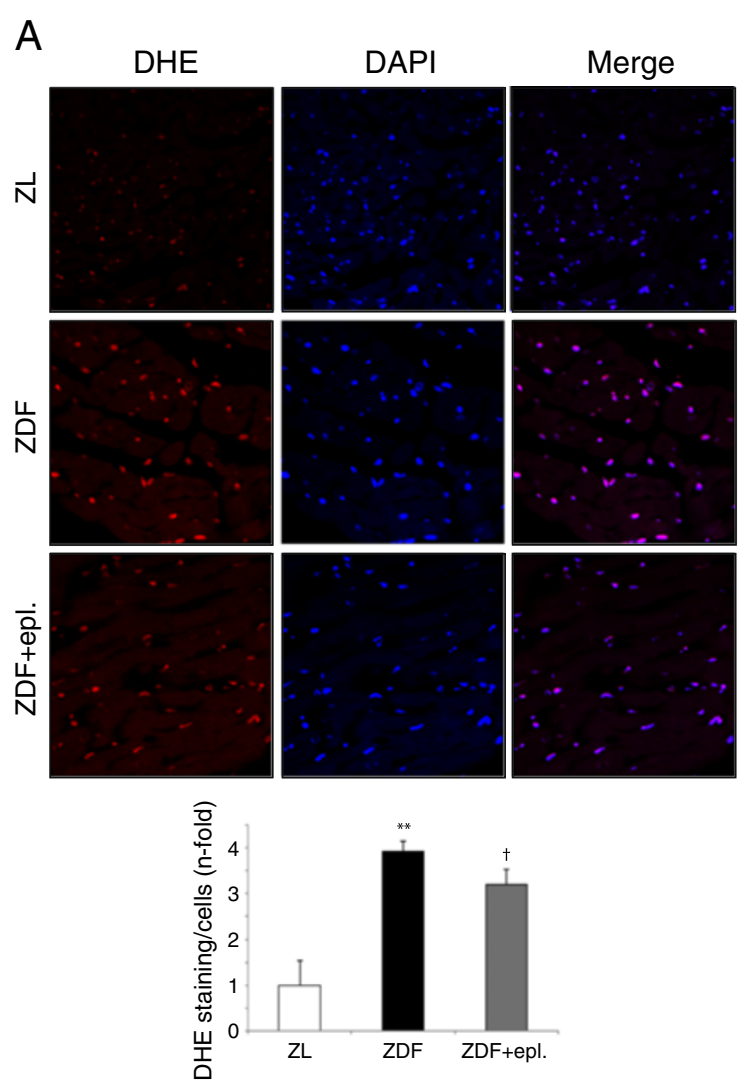

B
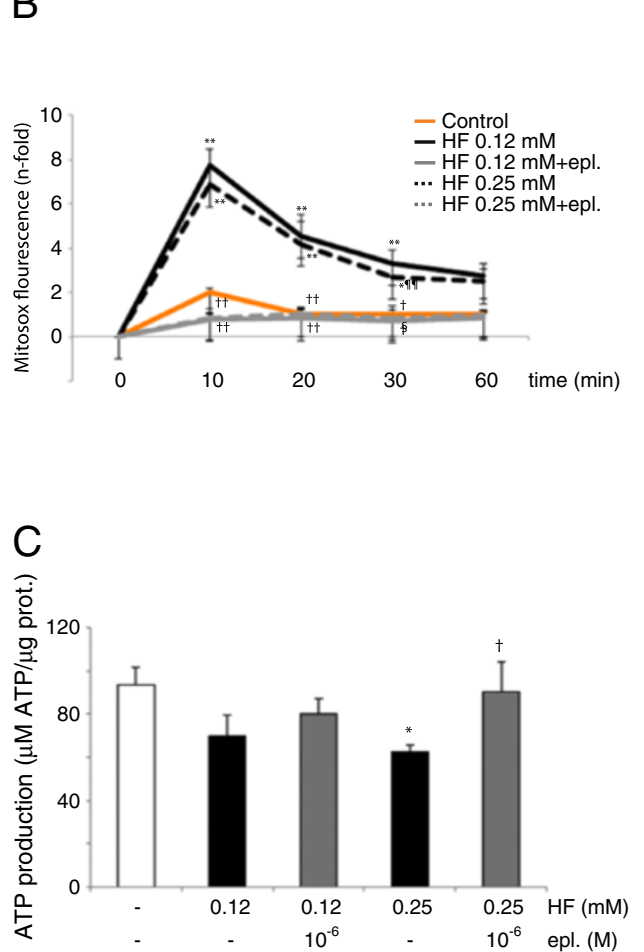
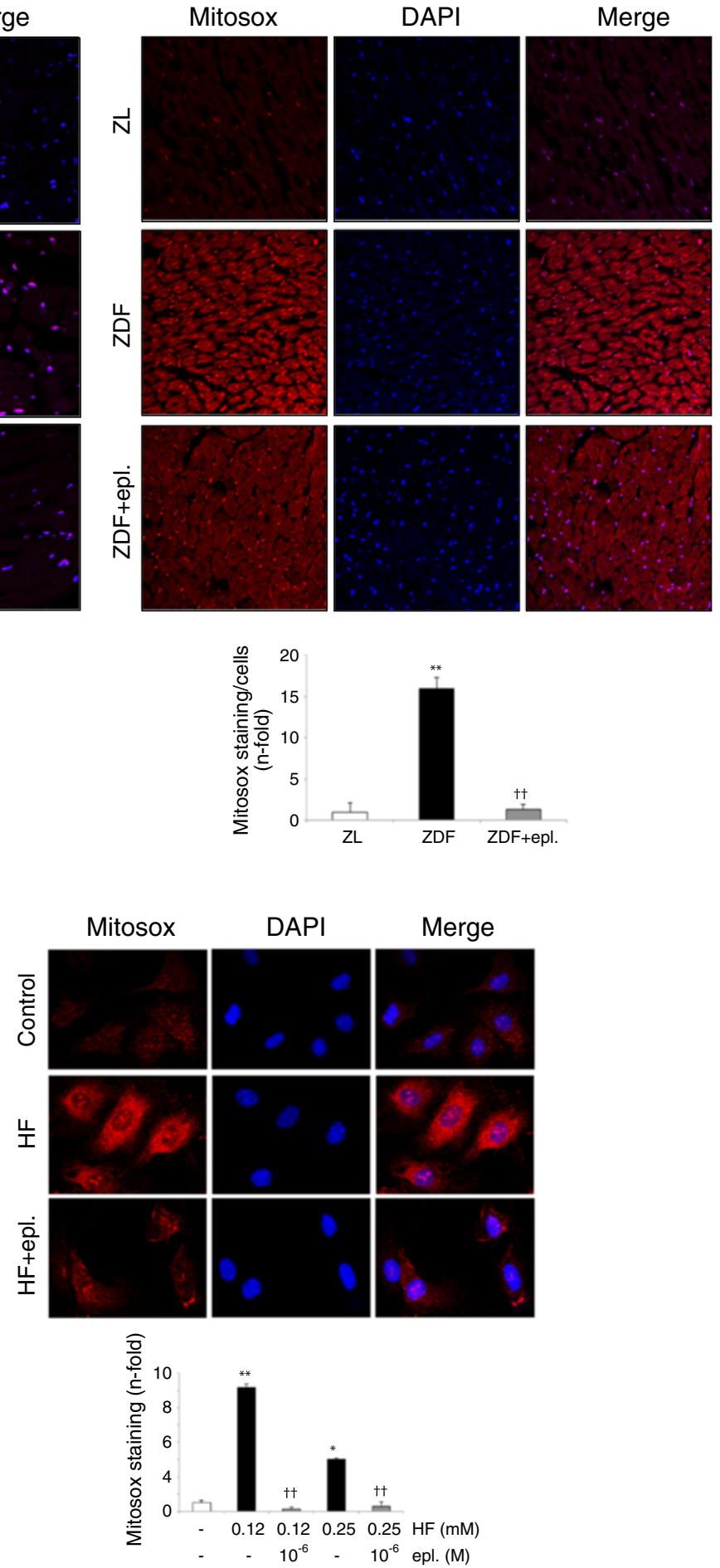

Figure 6 (See legend on next page.) 


\section{(See figure on previous page.)}

Figure 6 Anti-oxidant effects of eplerenone in ZDF hearts and HF-stimulated cardiomyocytes. (A) DHE and Mitosox staining (red) in ZDF and ZDF-treated myocardia. Nuclear labelling by DAPI (blue) is also shown. $N=6$, each group. (B) By flow cytometry (left), mitosox staining in 0-60 min HF and HF+eplerenone $\left(10^{-6} \mathrm{M}\right)$ incubated cardiomyocytes. By immunofluorescence (right), mitosox staining after $10 \mathrm{~min}$ of $\mathrm{HF}$ stimulation $\left(0.12 \mathrm{mM}\right.$ ). (C) ATP production in $12 \mathrm{~h}$ HF-stimulated cardiomyocytes. ${ }^{*} \mathrm{p}<0.05$ and ${ }^{* *} \mathrm{p}<0.01$ vs. control. $+p<0.05$ and $++p<0.01$ vs. related $\mathrm{ZDF}$ or $\mathrm{HF}$.
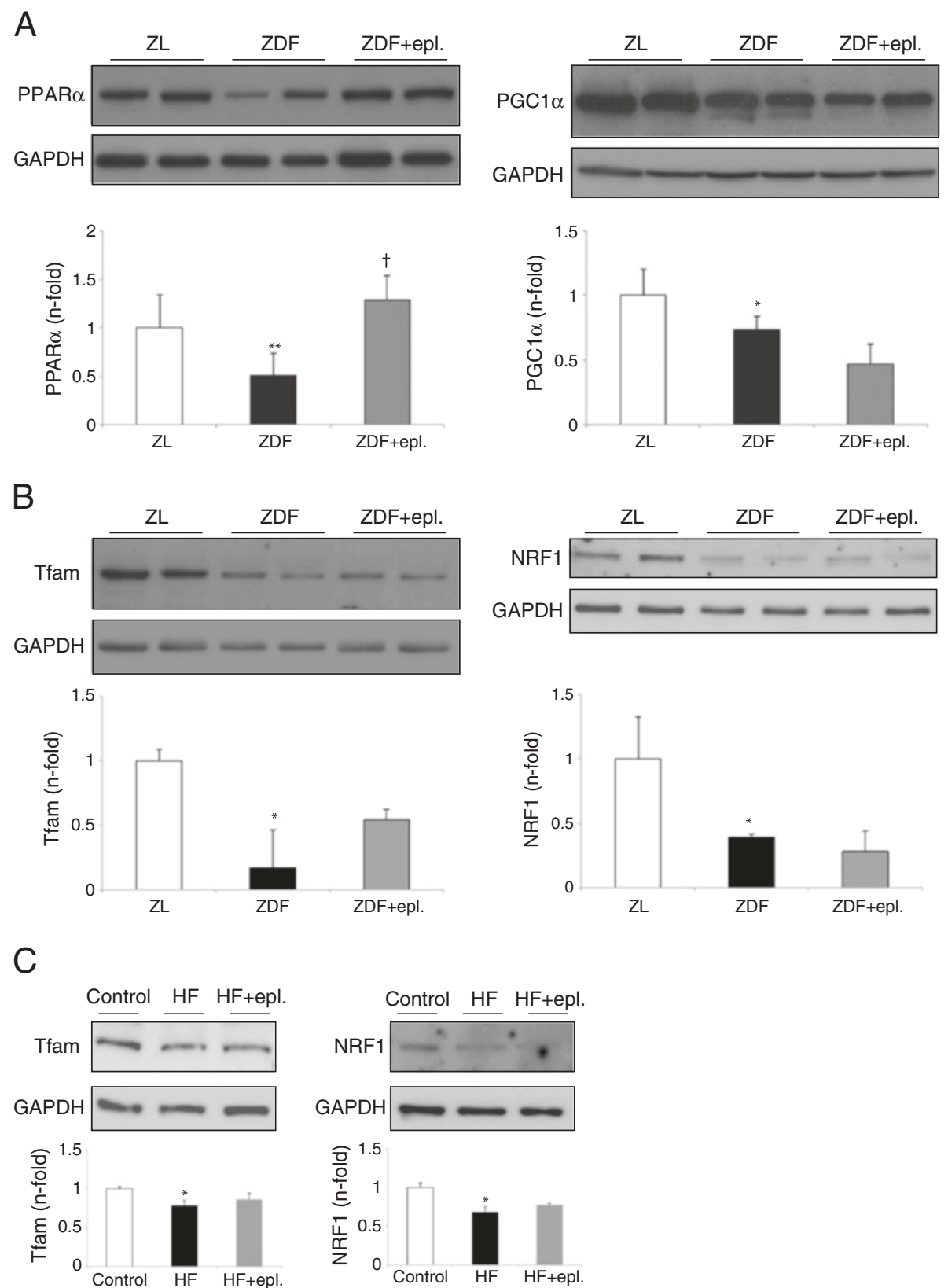

Figure 7 Mitochondrial-related factors in ZDF myocardia and HF-incubated cardiomyocytes. (A) PPARa ( 50 kDa), PGC1a ( 120 kDa), and (B) Tfam ( $\sim 25 \mathrm{kDa})$ and NRF1 ( $\sim 5 \mathrm{kDa}$ ) levels in the ZDF model. (C) Tfam and NRF1 protein content in $12 \mathrm{~h}$ HF-stimulated cardiomyocytes. ${ }^{*} \mathrm{p}<0.05$ and ${ }^{* *} \mathrm{p}<0.01$ vs. control. $+\mathrm{p}<0.05$ vs. related ZDF or HF. 


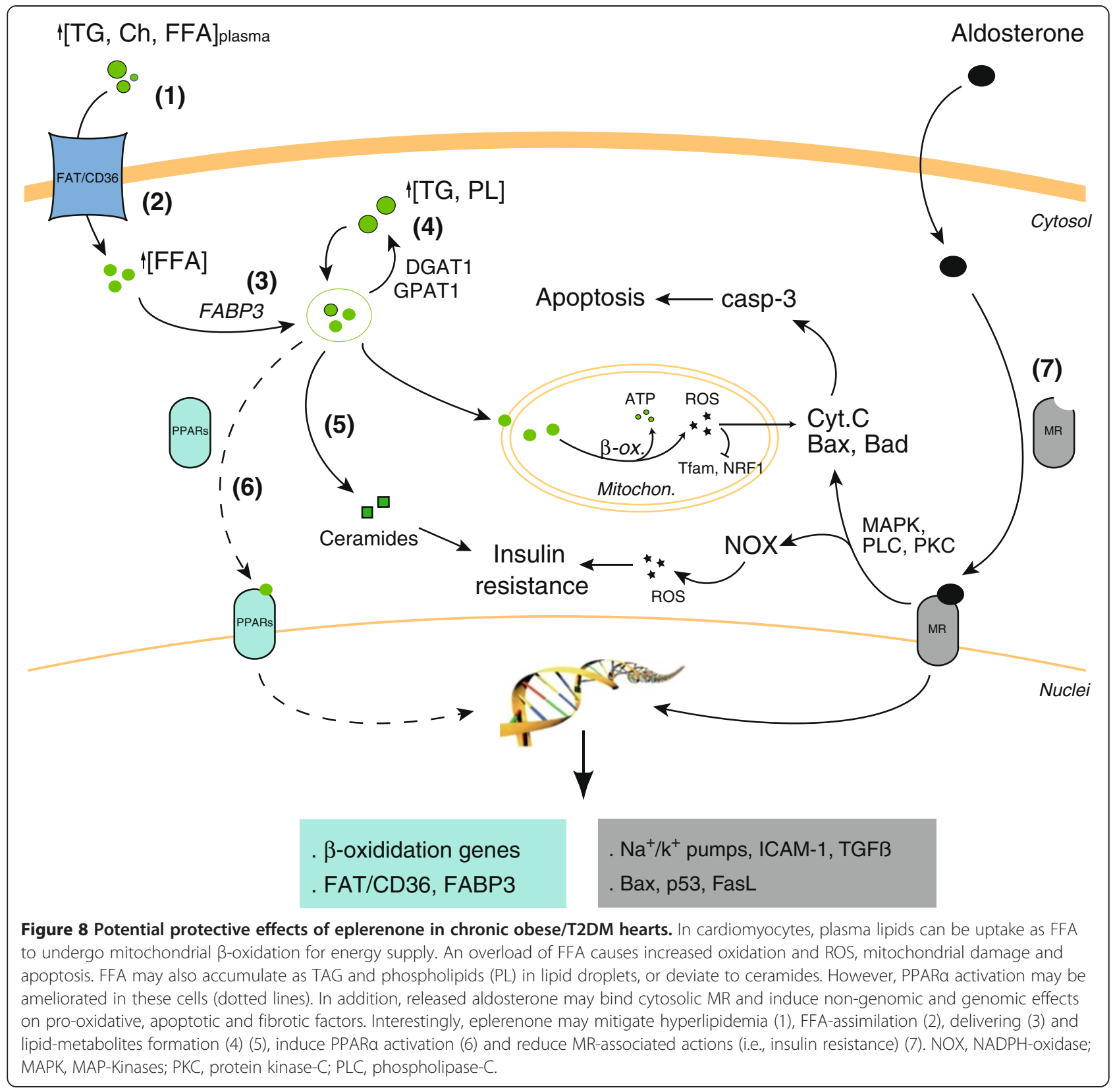

and thus, possibly due at least in part to the lipotoxicity lessening. Eplerenone decreased also $\beta$-oxidation in HF-incubated cells, as a source of ROS. Additionally, previous works also demonstrated protective properties of eplerenone in hyperosmotic cardiomyocytes [45], and some pro-apoptotic and pro-inflammatory/oxidative factors may be involved $[46,47]$. Altogether, by MR blockade and steatosis reduction, eplerenone could decrease aldosterone- and FFA-associated pro-oxidative, apoptotic and fibrotic actions [34] (Figure 8). Further investigations focusing on these particular mechanisms will add new insights to the knowledge of eplerenone protection in DCM. However, long-term eplerenone administration could lead to hyperkalemia, resulting in depolarization of the membrane potentials of cardiac cells and fatal arrhythmias [14]. Also eplerenone may induce off-target effects through the aldosterone competitive antagonism of the androgen receptor, affecting hormone secretion and function [48].

\section{Study limitations}

Glucocorticoids were detected in cultured media (Additional file 3: Figure S2A). In particular, plasma cortisol was $~ 30 \%$ higher in ZDF than in ZL rats. Since glucocorticoids can also bind to MR, we cannot exclude their potential effects in hearts and cardiomyocytes. In addition, the 
quantification of food intake could add important information since the decreased plasma FFA/TAG levels after eplerenone may be caused by differences in food consumption. Nevertheless, previous data in rat demonstrated no variation in food and water consumption after eplerenone administration [49].

\section{Conclusions}

Intracellular accumulation of lipids in the experimental obese/T2DM heart appears to play an important role in the pathogenesis of DCM. However, eplerenone decreased hyperlipidemia, myocardial FFA-uptake and steatosis, insulin resistance, and ceramides and ROS accumulation, which all may contribute to the improvement of energy consecution, cardiac remodelling and function. Even in the presence of high glucose concentration, our work supports the importance of controlling myocardial lipotoxicity for preventing the development of DCM, and eplerenone could attend as a valid therapy.

\section{Additional files}

Additional file 1: Supplemental Material. Details of the ZDF model and used techniques.

Additional file 2: Figure S1. Eplerenone attenuated fibrosis and ECM proteins in the ZDF myocardium. (A) By Masson, detection of ECM deposition (blue-green) in ZDF and ZDF+eplerenone hearts (top). (B) Type-IV collagen and fibronectin mRNA expression in the rats. $N=6$, each group. (C) HF induced apoptosis in cultured cardiomyocytes. Cardiomyocytes were stimulated with HF (0.12-0.5 mM) or glucose (HG, 25-33 mM) for 3-24 h, and apoptosis was quantified by flow cytometry. The percentage of apoptotic cells (sub G0/G1 cell cycle phase) is represented. (D) Caspase-3 activation after 3-14 h of HF and/or HG incubation, and nuclei piknosis (detailed in a bright field) and cell loss in $14 \mathrm{~h}$-stimulated cardiomyocytes. ${ }^{*} p<0.05$ and ${ }^{* *} p<0.01$ vs. related control. $+p<0.05$ and $++p<0.01$ vs. ZDF rats.

Additional file 3: Figure S2. (A) Aldosterone and glucocorticoids release from cardiomyocytes. Aldosterone and glucocorticoids (GC) were measured in cultured media after $12 \mathrm{~h} \mathrm{HF}$ and HF+eplerenone incubations. (B) Cardiac IRS-1 expression. Total IRS-1 levels ( 130 kDa) were detected in rat myocardia. ${ }^{*} p<0.05$ vs. related control. $\dagger+p<0.01$ vs. ZDF rats.

\section{Competing interests}

The authors declare that they have no competing interests.

\section{Authors' contributions}

ER and MK-M carried out the most of the molecular studies. SA-C performed the animal model and AC-V measured the cardiac structure and function. BP participated in the histological approaches. FJR, AF and CB performed lipid quantification. JE, JT and OL designed the study and performed the statistical analysis. OL coordinated and wrote the work. All authors read and approved the final manuscript.

\section{Acknowledgements}

This work was supported by national grants from Ministerio de Educación y Ciencia (SAF2009-08367), Comunidad de Madrid (CCG10-UAM/BIO-5289), FISS (PI10/00072), and a grant from by Pfizer (NY, USA), Spanish Ministry of Economy and Competitiveness (MINECO) CTQ2011-23562. These grants were used to provide consumables and animals required. The funders had no role in study design, data collection and analysis, decision to publish, or preparation of the manuscript. AF received funding from the European Union Seventh Framework Programme [FP7/2007-2013] under grant agreement nº 264864.

\section{Author details}

${ }^{1}$ Cardiovascular Pathology laboratory, IIS-Fundación Jiménez Díaz, Autónoma University, Av. Reyes Católicos 2, Madrid 28040 Spain. ${ }^{2}$ Spanish Biomedical Research Centre in Diabetes and Associated Metabolic Disorders (CIBERDEM) network, Madrid, Spain. ${ }^{3}$ Veterinary School, Complutense University, Madrid, Spain. ${ }^{4}$ Center for Metabolomics and Bioanalysis (CEMBIO), Facultad de Farmacia, Universidad CEU San Pablo, Campus Montepríncipe, 28668 Madrid, Spain.

Received: 30 July 2013 Accepted: 9 November 2013

Published: 21 November 2013

\section{References}

1. Aneja A, Tang WHW, Bansilal S, Garcia MJ, Farkouh ME: Diabetic cardiomyopathy: insights into pathogenesis, diagnostic challenges, and therapeutic options. Am J Med 2008, 121:748-757.

2. $\mathrm{Ng} \mathrm{ACT}$, Delgado $\mathrm{V}$, Bertini $M$, van der Meer RW, Rijzewijk $L$, Hooi Ewe $S$, Siebelink H-M, Smit JWA, Diamant M, Romijn JA, de Roos A, Leung DY, Lamb HJ, Bax JJ: Myocardial steatosis and biventricular strain and strain rate imaging in patients with type 2 diabetes mellitus. Circulation 2010, 122:2538-2544.

3. Duncan JG: Mitochondrial dysfunction in diabetic cardiomyopathy. Biochim Biophys Acta 1813, 2011:1351-1359.

4. Galuppo P, Bauersachs J: Mineralocorticoid receptor activation in myocardial infarction and failure: recent advances. Eur J Clin Invest 2012, 42:1112-1120.

5. Machackova J, Liu X, Lukas A, Dhalla NS: Renin-angiotensin blockade attenuates cardiac myofibrillar remodelling in chronic diabetes. $\mathrm{Mo} / \mathrm{Cell}$ Biochem 2004, 261:271-278.

6. Frustaci A, Kajstura J, Chimenti C, Jakoniuk I, Leri A, Maseri A, Nadal-Ginard B, Anversa P: Myocardial cell death in human diabetes. Circ Res 2000, 87:1123-1132.

7. Ruiz-Ortega M, Lorenzo O, Rupérez M, Esteban V, Mezzano S, Egido J: Renin-angiotensin system and renal damage: emerging data on angiotensin II as a proinflammatory mediator. Contrib Nephrol 2001, 135:123-137.

8. Pitt B, Stier CT Jr, Rajagopalan S: Mineralocorticoid receptor blockade: new insights into the mechanism of action in patients with cardiovascular disease. J Renin Angiotensin Aldosterone Syst 2003, 4:164-168.

9. Dooley R, Harvey BJ, Thomas W: The regulation of cell growth and survival by aldosterone. Front Biosci 2011, 16:440-457.

10. Pitt B, Reichek N, Willenbrock R, Zannad F, Phillips RA, Roniker B, Kleiman J, Krause S, Burns D, Williams GH: Effects of eplerenone, enalapril, and eplerenone/enalapril in patients with essential hypertension and left ventricular hypertrophy: the 4E-left ventricular hypertrophy study. Circulation 2003, 108:1831-1838.

11. Markowitz M, Messineo F, Coplan NL: Aldosterone receptor antagonists in cardiovascular disease: a review of the recent literature and insight into potential future indications. Clin Cardio/ 2012, 35(10):605-609.

12. Daniels $A$, Linz D, van Bilsen $M$, Rütten $H$, Sadowski T, Ruf S, Juretschke H-P, Neumann-Haefelin C, Munts C, van der Vusse GJ, van Nieuwenhoven FA: Long-term severe diabetes only leads to mild cardiac diastolic dysfunction in Zucker diabetic fatty rats. Eur J Heart Fail 2012, 14:193-201.

13. Hickson-Bick DLM, Sparagna GC, Buja LM, McMillin JB: Palmitate-induced apoptosis in neonatal cardiomyocytes is not dependent on the generation of ROS. Am J Physiol Heart Circ Physiol 2002, 282:H656-H664.

14. Baker WL, White WB: Safety of mineralocorticoid receptor antagonists in patients receiving hemodialysis. Ann Pharmacother 2012, 46:889-894

15. Mega C, de Lemos ET, Vala H, Fernandes R, Oliveira J, Mascarenhas-Melo F, Teixeira F, Reis F: Diabetic nephropathy amelioration by a low-dose sitagliptin in an animal model of type 2 diabetes (Zucker diabetic fatty rat). Exp Diabetes Res 2011, 2011:162092.

16. Miric G, Dallemagne C, Endre Z, Margolin S, Taylor SM, Brown L: Reversal of cardiac and renal fibrosis by pirfenidone and spironolactone in streptozotocin-diabetic rats. Br J Pharmacol 2001, 133:687-694.

17. Stier CT Jr: Eplerenone: a selective aldosterone blocker. Cardiovasc Drug Rev 2003, 21:169-184.

18. Ueno M, Suzuki J, Zenimaru Y, Takahashi S, Koizumi T, Noriki S, Yamaguchi O, Otsu K, Shen W-J, Kraemer FB, Miyamori I: Cardiac overexpression of hormone-sensitive lipase inhibits myocardial steatosis and fibrosis in 
streptozotocin diabetic mice. Am J Physiol Endocrinol Metab 2008, 294:E1109-E1118.

19. Luiken JJFP, Coort SLM, Willems J, Coumans WA, Bonen A, van der Vusse GJ, Glatz JFC: Contraction-induced fatty acid translocase/CD36 translocation in rat cardiac myocytes is mediated through AMP-activated protein kinase signaling. Diabetes 2003, 52:1627-1634.

20. Brinkmann JFF, Pelsers MMAL, van Nieuwenhoven FA, Tandon NN, van der Vusse GJ, Glatz JFC: Purification, immunochemical quantification and localization in rat heart of putative fatty acid translocase (FAT/CD36). Mol Cell Biochem 2006, 284:127-134.

21. Zhou YT, Grayburn P, Karim A, Shimabukuro M, Higa M, Baetens D, Orci L, Unger RH: Lipotoxic heart disease in obese rats: implications for human obesity. Proc Natl Acad Sci USA 2000, 97:1784-1789.

22. Baranowski M, Błachnio A, Zabielski P, Górski J: PPARalpha agonist induces the accumulation of ceramide in the heart of rats fed high-fat diet. J Physiol Pharmacol 2007, 58:57-72.

23. Glenn DJ, Wang F, Nishimoto M, Cruz MC, Uchida Y, Holleran WM, Zhang Y, Yeghiazarians Y, Gardner DG: A murine model of isolated cardiac steatosis leads to cardiomyopathy. Hypertension 2011, 57:216-222.

24. Van Nieuwenhoven FA, Luiken JJ, De Jong YF, Grimaldi PA, Van der Vusse GJ, Glatz JF: Stable transfection of fatty acid translocase (CD36) in a rat heart muscle cell line (H9c2). J Lipid Res 1998, 39:2039-2047.

25. Philp A, Perez-Schindler J, Green C, Hamilton DL, Baar K: Pyruvate suppresses PGC1alpha expression and substrate utilization despite increased respiratory chain content in C2C12 myotubes. Am J Physiol Cell Physiol 2010, 299:C240-C250.

26. Ramachandran B, Yu G, Gulick T: Nuclear respiratory factor 1 controls myocyte enhancer factor $2 \mathrm{~A}$ transcription to provide a mechanism for coordinate expression of respiratory chain subunits. J Biol Chem 2008, 283:11935-11946.

27. Picatoste B, Ramírez E, Caro-Vadillo A, Iborra C, Egido J, Tunon J, Lorenzo O: Sitagliptin reduces cardiac apoptosis, hypertrophy and fibrosis primarily by insulin-dependent mechanisms in experimental type-Il diabetes. Potential roles of GLP-1 isoforms. PLOS ONE 2013, 8(10):e78330.

28. Regan TJ: Congestive heart failure in the diabetic. Annu Rev Med 1983, 34:161-168.

29. Resch M, Schmid P, Amann K, Fredersdorf S, Weil J, Schach C, Birner C, Griese DP, Kreuzer P, Brunner S, Luchner A, Riegger GAJ, Endemann DH: Eplerenone prevents salt-induced vascular stiffness in Zucker diabetic fatty rats: a preliminary report. Cardiovasc Diabetol 2011, 10:94.

30. Sárközy M, Zvara A, Gyémánt N, Fekete V, Kocsis GF, Pipis J, Szűcs G, Csonka C, Puskás LG, Ferdinandy P, Csont T: Metabolic syndrome influences cardiac gene expression pattern at the transcript level in male ZDF rats. Cardiovasc Diabetol 2013, 12:16.

31. Ares-Carrasco S, Picatoste B, Camafeita E, Carrasco-Navarro S, Zubiri l, Ortiz A, Egido J, López JA, Tuñón J, Lorenzo O: Proteome changes in the myocardium of experimental chronic diabetes and hypertension: Role of PPARa in the associated hypertrophy. J Proteomics 2012, 75:1816-1829.

32. Rubin J, Matsushita K, Ballantyne CM, Hoogeveen R, Coresh J, Selvin E: Chronic hyperglycemia and subclinical myocardial injury. J Am Coll Cardiol 2012, 59:484-489.

33. Castagno D, Baird-Gunning J, Jhund PS, Biondi-Zoccai G, MacDonald MR, Petrie MC, Gaita F, McMurray JJV: Intensive glycemic control has no impact on the risk of heart failure in type 2 diabetic patients: evidence from a 37,229 patient meta-analysis. Am Heart J 2011, 162:938-948. e2.

34. Guo C, Ricchiuti V, Lian BQ, Yao TM, Coutinho P, Romero JR, Li J, Williams GH, Adler GK: Mineralocorticoid receptor blockade reverses obesity-related changes in expression of adiponectin, peroxisome proliferator-activated receptor-gamma, and proinflammatory adipokines. Circulation 2008, 117:2253-2261.

35. Sato A, Fukuda S: Clinical effects of eplerenone, a selective aldosterone blocker, in Japanese patients with essential hypertension. J Hum Hypertens 2010, 24:387-394.

36. Nguyen Dinh Cat A, Jaisser F: Extrarenal effects of aldosterone. Curr Opin Nephrol Hypertens 2012, 21:147-156.

37. Calle C, Campión J, García-Arencibia M, Maestro B, Dávila N: Transcriptional inhibition of the human insulin receptor gene by aldosterone. J Steroid Biochem Mol Biol 2003, 84:543-553.

38. Selvaraj J, Muthusamy T, Srinivasan C, Balasubramanian K: Impact of excess aldosterone on glucose homeostasis in adult male rat. Clin Chim Acta 2009, 407:51-57.
39. Holst D, Luquet $S$, Nogueira V, Kristiansen K, Leverve X, Grimaldi PA: Nutritional regulation and role of peroxisome proliferator-activated receptor delta in fatty acid catabolism in skeletal muscle. Biochim Biophys Acta 2003, 1633:43-50.

40. Young ME, Guthrie PH, Razeghi P, Leighton B, Abbasi S, Patil S, Youker KA, Taegtmeyer $\mathrm{H}$ : Impaired long-chain fatty acid oxidation and contractile dysfunction in the obese Zucker rat heart. Diabetes 2002, 51:2587-2595.

41. Lopaschuk GD, Ussher JR, Folmes CDL, Jaswal JS, Stanley WC: Myocardial fatty acid metabolism in health and disease. Physiol Rev 2010, 90:207-258.

42. Duncan JG, Bharadwaj KG, Fong JL, Mitra R, Sambandam N, Courtois MR, Lavine KJ, Goldberg IJ, Kelly DP: Rescue of cardiomyopathy in peroxisome proliferator-activated receptor-alpha transgenic mice by deletion of lipoprotein lipase identifies sources of cardiac lipids and peroxisome proliferator-activated receptor-alpha activators. Circulation 2010, 121:426-435.

43. Feingold K, Kim MS, Shigenaga J, Moser A, Grunfeld C: Altered expression of nuclear hormone receptors and coactivators in mouse heart during the acute-phase response. Am J Physiol Endocrinol Metab 2004, 286:E201-E207.

44. Lewin TM, de Jong H, Schwerbrock NJM, Hammond LE, Watkins SM, Combs TP, Coleman RA: Mice deficient in mitochondrial glycerol-3phosphate acyltransferase- 1 have diminished myocardial triacylglycerol accumulation during lipogenic diet and altered phospholipid fatty acid composition. Biochim Biophys Acta 2008, 1781:352-358.

45. Sánchez-Más J, Turpín MC, Lax A, Ruipérez JA, Valdés Chávarri M, Pascual-Figal DA: Differential actions of eplerenone and spironolactone on the protective effect of testosterone against cardiomyocyte apoptosis in vitro. Rev Esp Cardiol 2010, 63:779-787.

46. Mano A, Tatsumi T, Shiraishi J, Keira N, Nomura T, Takeda M, Nishikawa S, Yamanaka S, Matoba S, Kobara M, Tanaka H, Shirayama T, Takamatsu T, Nozawa $\mathrm{Y}$, Matsubara $\mathrm{H}$ : Aldosterone directly induces myocyte apoptosis through calcineurin-dependent pathways. Circulation 2004, 110:317-323.

47. Tan W-Q, Wang J-X, Lin Z-Q, Li Y-R, Lin Y, Li P-F: Novel cardiac apoptotic pathway: the dephosphorylation of apoptosis repressor with caspase recruitment domain by calcineurin. Circulation 2008, 118:2268-2276.

48. Levin S, McMahon E, John-Baptiste A, Bell RR: Prostate effect in dogs with the aldosterone receptor blocker eplerenone. Toxicol Pathol 2013, 41:271-279.

49. Ortiz RM, Graciano ML, Seth D, Awayda MS, Navar LG: Aldosterone receptor antagonism exacerbates intrarenal angiotensin II augmentation in ANG II-dependent hypertension. Am J Physiol Renal Physiol 2007, 293: F139-F147.

doi:10.1186/1475-2840-12-172

Cite this article as: Ramírez et al:: Eplerenone attenuated cardiac steatosis, apoptosis and diastolic dysfunction in experimental type-II diabetes. Cardiovascular Diabetology 2013 12:172.

\section{Submit your next manuscript to BioMed Central and take full advantage of:}

- Convenient online submission

- Thorough peer review

- No space constraints or color figure charges

- Immediate publication on acceptance

- Inclusion in PubMed, CAS, Scopus and Google Scholar

- Research which is freely available for redistribution

Submit your manuscript at www.biomedcentral.com/submit
C) Biomed Central 